\title{
Forskolin : From an Ayurvedic Remedy to a Modern Agent
}

\author{
Hermann P. T. Ammon ${ }^{1,2}$ and Axel B. Müller ${ }^{1}$ \\ Received : June 28, 1985; Accepted : August 27, 1985
}

\begin{abstract}
Ancient Hindu Ayurvedic texts described the use of extracts from Coleus species. An isolated diterpene from Coleus forskohlii, called forskolin, was demonstrated to be a hypotensive agent with spasmolytic, cardiotonic and platelet aggregation inhibitory activity. It has been shown to be a powerful activator of the enzyme adenylate cyclase in various tissues. Forskolin is thought to act on the catalytic subunit and also on the coupling mechanism of guanine regulatory sites ( Ns and $\mathrm{Ni}$ ) with the catalytic subunit. It is now clear that forskolin elicits physiological responses which have been shown to be cAMP-dependent.
\end{abstract}

\section{Introduction}

Ayurveda based on the Indian vedas was developed more than 3000 years ago. Ayurveda defines life as the union of body, senses, mind, and soul. In Ayurveda, human beings, animals, and plants represent a microcosmos in a macrocosmos and the microcosmos consists of the same elements as the macrocosmos including fire (Tejas), sky (Akasa), soil (Prthivi), water (Jala), and air (Vayu). According to Ayurveda, soma (consisting of above elements) is closely related and governed by psychis (Mana). Diagnosis and treatment of diseases follow the philosophy of the socalled tridoshas "vata", "pitta", "kapha". As far as the use of drugs - especially medicinal plants - is concerned their composition is less based on pharmacological actions, which were not known at that time, but rather on the basis of tridoshas (for substitutions of elements). In this connection the properties of medicinal plants including taste (Rasa), change during digestion (Vipaka), and physical properties (Guna) were thought to be indicative for the presence of above elements. Up to date the composition of Ayurvedic remedies appears to follow this line. There is no doubt that many of the Ayurvedic medicinal plants possess therapeutically useful effects. It is, however, very unlikely that such effects can be explained by the Ayurvedic philosophy of tridoshas and drug properties.

Nevertheless, it is still possible that medicinal plants used in Ayurvedic medicine may contain unknown active principles which may be useful drugs and/or tools for modern natural sciences and medicine [for review see (1)].

Since ancient times, preparations of Coleus species have been used for medical treatment in Hindu and Ayurvedic traditional medicine. The major uses are for heart diseases, abdominal colic, respiratory disorders, painful micturation, insomnia, and convulsions.

\footnotetext{
${ }^{1}$ Department of Pharmacology, Institute of Pharmaceutical Sciences, University of Tuebingen, D-7400 Tübingen, Federal Republic of Germany

${ }^{2}$ Address for correspondence
}

Reports of screening of Indian plants for activity by the Central Drug Research Institute (CDRI), Lucknow, in 1974 revealed the blood pressure lowering and antispasmodic effects of extracts of the roots of Coleus forskohlii $(2,3)$. The active principle, a diterpene, was isolated at the same institution and named Coleonol, as well as by a group at Hoechst Pharmaceuticals, Bombay (now Hoechst India Limited) and named Forskolin. This diterpene is responsible for virtually all reported pharmacological activities. Some confusion, however, existed over several years in the literature regarding the chemical structure of these molecules. Whereas the Hoechst group determined the 7-acetoxy group of forskolin to possess the $\beta$-configuration (4), the CDRI group determined the stereochemistry to be $\alpha$ at that position (5). In a recent publication, the identity of the two molecules was demonstrated unambiguously, corresponding to the structural assignment given to forskolin (6) (see Fig. 1).

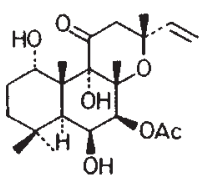

Fig. 1. Structure of forskolin

\section{Cardiovascular effects}

The cardiovascular effects of forskolin and coleonol have been reported in detail [Lindner et al., 1978 (7); Dubey et al., 1981 (8)]. Both compounds displayed almost similar properties. Fig. 2 shows a summary of the cardiovascular effects in the anaesthesized dog evoked by forskolin: a fall in blood pressure and an increase in heart rate, $\mathrm{d} p / \mathrm{d} t$, cardiac output and stroke volume. Such an effect of forskolin could not only be observed in the anaesthesized dog, but also in cats, in renal hypertensive rats and in the spontaneous hypertensive rat.

In the isolated guinea pig heart, Lindner et al. (7) also reported (Fig. 3) that forskolin in a dose-related manner increased contractility of heart muscle; in addition also coronary blood flow was augmented.

Extensive work was done both with forskolin and coleonol in order to determine the localization and the mechanism of their hypotensive action $(7,8)$. Thus, hypotensive effects by forskolin and coleonol were achieved in the deafferented as well as in the spinal transected cat. This observation was substantiated by the data indicating that coleonol when administered intracerebroventrically also did not produce hypotension. Overall, the 

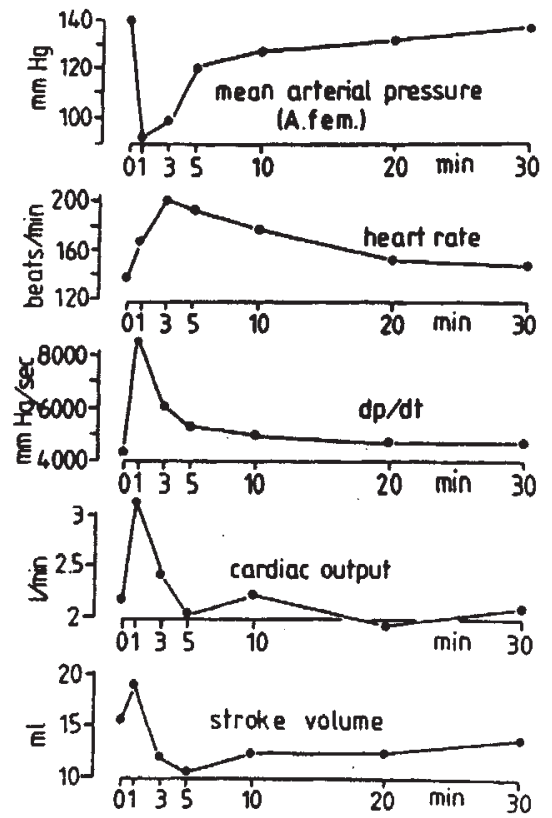

Fig. 2. Influence of forskolin $(100 \mu \mathrm{g} / \mathrm{kg}) i$. v. on parameters of circulation ( $n=5$ dogs) (from 7 )

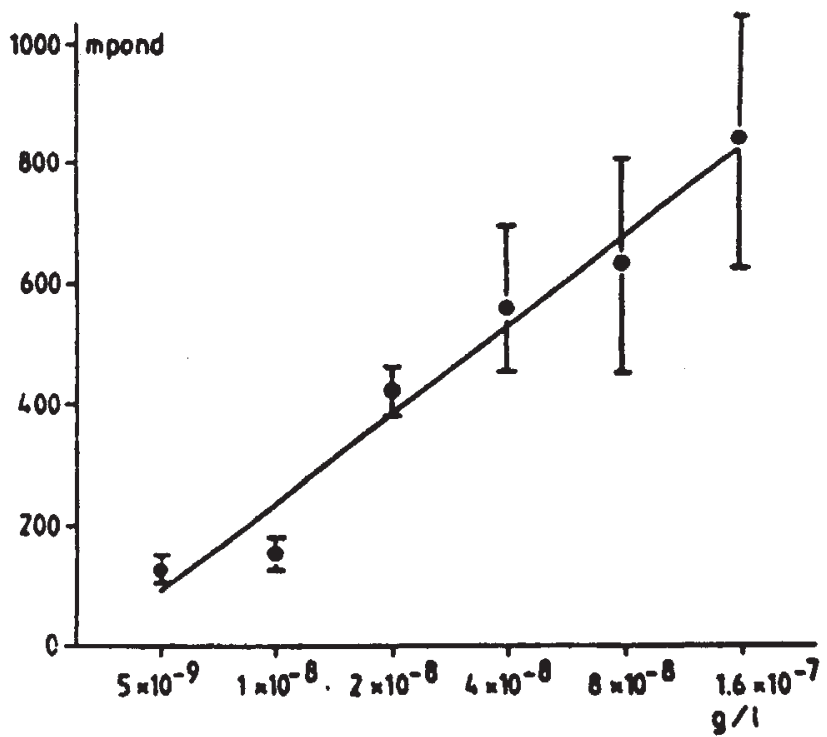

Fig. 3. Augmentation of contractile force of the isolated guinea pig atrium by forskolin $(n=5)($ from 7$)$

data suggested that lowering of blood pressure is not mediated by central effects of forskolin or coleonol, but is rather due to direct peripheral vasodilatatory actions.

\section{Mechanism of action}

Under physiological conditions, peripheral vasodilatation is mainly mediated by $\beta$-receptor-stimulation, $\mathrm{H}_{1}$-receptorstimulation and stimulation of muscarinic receptors. However, studies with forskolin and coleonol showed that their hypotensive activity could not be blocked by adrenergic, muscarinic or $\mathrm{H}_{1}$-antagonists [for reviews see $(9,10)$ ], indicating that vasodilatation in response to forskolin or coleonol may either be due to their interaction with other types of receptors or may be due to a postreceptor action.
Further studies which were performed to clarify the mechanism of positive inotropic action showed that the mechanism of forskolin was different from the action of cardioglycosides or phosphodiesterase inhibitors. However, despite the fact that the effects of forskolin or coleonol, respectively, could not be blocked by $\beta$-antagonists it seemed that their effects on cardiovascular systems were somehow similar to those occurring during $\beta$-stimulation.

In the further search for the mechanism of action Metzger and Lindner demonstrated that a protein kinase in rabbit heart slices was activated by forskolin following the stimulation of adenylate cyclase. Subsequently forskolin has been shown to stimulate adenylate cyclase from a number of tissues [for review see Daly, 1984 (11)].

The increase of cAMP in heart muscle is known to increase its contractility via opening of the slow $\mathrm{Ca}$-channel thus leading to elevation of intracellular calcium. In addition, increase of cAMP in the smooth muscle causes relaxation. Taking these effects into mind, it is now clear that the cardiovascular effects of forskolin and of coloneol as discussed so far can be explained by their increases of cAMP levels in heart and arterial smooth muscle.

\section{Adenylate cyclase}

Further studies with forskolin concentrated on the question of the localization of its action in the adenylate cyclase system.

According to the scheme shown in Fig. 4 as published by Stiles et al. (12) stimulatory as well as inhibitory hormones may interact with the adenylate cyclase system. The first step is that a stimulatory hormone (Hs) binds to its receptor in the cytoplasma membranes. After coupling of the hormone receptor complex to the guanine nucleotide regulatory component -also called stimulatory $N$-protein (Ns) - GTP interacts with the Nsprotein. The GTP-Ns-complex dissociates from the hormonereceptor complex and activates the catalytic unit of adenylate cyclase. The GTP concentration necessary for activation of Nsprotein being approximately $20 \mathrm{nM}$ (13). In a similar fashion inhibition of the catalytic unit occurs: Following the interaction

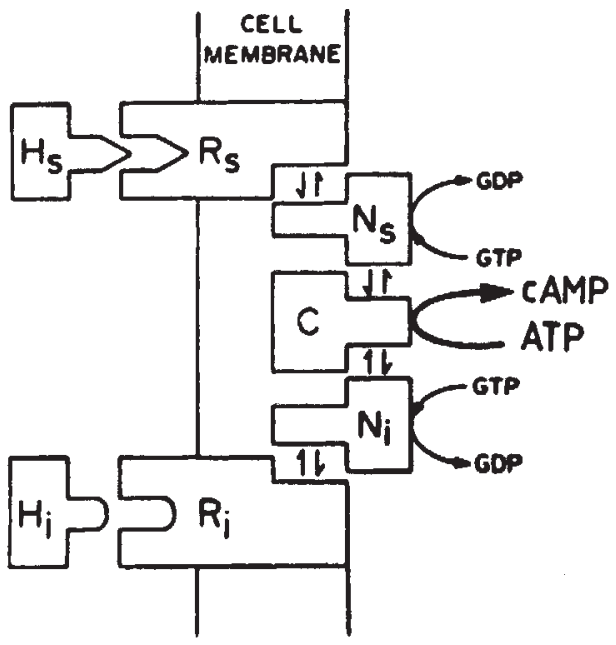

Fig. 4. Model of hormone - sensitive adenylate cyclase (from 12) C catalytic unit

H hormone

i inhibitory

N guanine nucleotide regulatory component

$R$ receptor

s stimulatory 
of an inhibitory hormone with its receptor (Ri) the inhibitory hormone receptor complex couples to the inhibitory $N$-protein (Ni). After interaction of GTP - now $100 \mathrm{nM}$ (13) are necessary - with the Ni-protein the inhibitory hormone-receptor complex dissociates from the $\mathrm{Ni}$ and the latter causes inhibition of the catalytic unit of the adenylate cyclase. Thus, under in vivo conditions the activity of catalytic unit of the adenylate cyclase is the result of stimulation and inhibition by hormones via Ns and Ni-proteins [for reviews see (13) and (14)]. In the scheme discussed so far the following possibilities of activation of the catalytic unit by forskolin are conceivable:

1. Interaction with a hormone receptor.

2. Direct activation of the catalytic unit.

3. Activation of the stimulatory nucleotide binding protein (Ns).

From studies employing blockers of $\beta-, \mathrm{H}_{1^{-}}$, and muscarinic receptors, as discussed before, it was evident that the effect of forskolin on adenylate cyclase could not be blocked, and therefore forskolin does not seem to act via any of the major classes of receptors.

Further studies concentrated on the question whether or not the action of forskolin on adenylate cyclase might occur through its interaction with the catalytic unit and/or the regulatory subunits ( $N$-proteins).

The introduction of cyc(-)-mutants of S 49 lymphoma cells which lack a functional Ns-subunit in their adenylate cyclase system presented evidence that forskolin activates adenylate cyclase in the absence of Ns. Activation also occurred in the absence of a functional Ni-protein. It appears therfore that forskolin acts on the catalytic unit or a closely related protein [for review see (11)]

However, although the action of forskolin on the catalytic unit appears not to require a functional Ns subunit there is now indirect evidence that its effect on the adenylate cyclase system is also related to an interaction with the Ns-protein. This evidence comes from studies with intact cells, in which forskolin markedly potentiated the activation of the cyclic AMP generating systems when stimulated by hormones (15). In most cases forskolin not only increased the maximal possible response but also the potency of the receptor agonist. In addition various receptor agonists when used at low concentrations increased the potency of forskolin and the maximal accumulation of cyclic AMP elicited by forskolin. These results suggest that activation of adenylate cyclase by hormones and forskolin are strongly coupled to each other in a cooperative manner [for review see (11)]. Further evidence that forskolin apparently augments the receptor-mediated input of the stimulatory Ns-protein to cAMP formation comes from some cells in which such input is impaired. Thus, in adipocytes from hypothyreoid rats (16), and in $H$ 21a lymphoma cells (17), forskolin significantly augmented the responses to isoproterenol. On the other hand forskolin could not restore the effect of isoproterenol in mutants of lymphoma cells which are lacking Ns-protein (17). This and further evidence as previously reviewed by Daly (11) suggest that forskolin also activates the stimulatory Ns-protein of the adenylate cyclase system.

However, evidence that forskolin acts on the inhibitory $\mathrm{Ni}$ protein system, as also previously reviewed (18), comes from the fact that, despite different mechanisms, the stimulation of rat cerebral cortical adenylate cyclase by a combination of forskolin and Gpp(NH)p (guanosine [5'-( $\beta, \gamma$-imido)triphosphate]) resulted in less activity than the sum of their separate stimulations. It has been proposed that $\mathrm{Gpp}(\mathrm{NH}) \mathrm{p}$ inhibition of forskolin-activated adenylate cyclase is a characteristic of adeny- late cyclase systems which contain functional Ni-subunits. In addition it has also been suggested that forskolin stabilizes the interaction of the Ni-Gpp(NH)p complex with the catalytic unit.

\section{Cyclic AMP}

Increases of cAMP by forskolin have been found in numerous tissues. Fig. 5 shows the effect of forskolin on cAMP in rat pancreatic islets where a 9 fold elevation could be observed in the presence of $500 \mu \mathrm{M}$; the half maximal effect being in the range of $25 \mu \mathrm{M}(19)$.

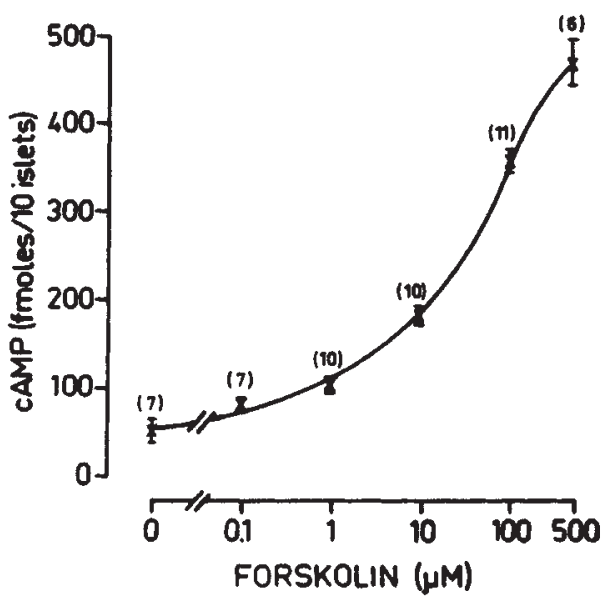

Fig. 5. Effect of forskolin on cAMP elevation in rat pancreatic islets (from 19)

\section{cAMP and biological effects}

The physiological principle of cAMP ("second messenger") mediated biological responses is that, dependent on the organ or the organ functions, the latter are stimulated via different hormones reacting selectively with hormone receptors, thus guaranteeing the selectivity of their actions. In contrast, forskolin appears to simultaneously stimulate cAMP formation and cAMP mediated functions in all eucaryotic cells except sperm adenylate cyclase (20).

Table I gives examples - although being incomplete - where a rise of cAMP by means other than forskolin, as well as by forskolin itself, has been shown to stimulate tissue functions. For further increases of cAMP and related biological effects mediated by forskolin see Daly (11).

Previously, our laboratory reported some information on the effect of forskolin on glucose-induced insulin release in vivo as well as in the perifused pancreatic islet system (19) (Fig. 6). The lower curve shows the well known biphasic secretory effect of $11.1 \mathrm{mM}$ glucose. In the upper curve this effect was markedly potentiated by $10 \mu \mathrm{M}$ forskolin. Similar results have been obtained in vivo during an $i$. $v$. glucose test.

Findings of Agarwal and Parks (21) raise the possibility that forskolin could be a potential antimetastatic agent. In studies with a subline of B 16 murine melanoma (highly metastatic to lungs) forskolin strongly inhibited the melanoma cell- induced platelet aggregation and reduced tumor colonization in the lungs by more than $70 \%$.

\section{Clinical studies}

Clinically so far the effects of forskolin on heart, blood pressure, bronchospasm and on the eye became of interest. 
Table I. Physiological and biochemical effects of cAMP and forskolin

\begin{tabular}{llll}
\hline Tissue & Effect & cAMP & Forskolin \\
\hline Platelets & $\begin{array}{l}\text { Inhibition of } \\
\text { aggregation }\end{array}$ & $(26)$ & $(31)$ \\
Adipocytes & $\begin{array}{l}\text { Increased } \\
\text { lipolysis }\end{array}$ & $(27)$ & $(16)$ \\
Heart & $\begin{array}{l}\text { Increased force } \\
\text { of contraction }\end{array}$ & $(28)$ & $(7)$ \\
Islets of & $\begin{array}{l}\text { Potentiation of } \\
\text { insulin secretion }\end{array}$ & $(30)$ & $(19,32)$ \\
Thyroid & $\begin{array}{l}\text { Increased secretion, } \\
\text { iodide incorporation }\end{array}$ & $\begin{array}{l}\text { Increased steroid } \\
\text { genesis }\end{array}$ & $(34)$ \\
Adrenal & $\begin{array}{l}\text { Increased ACTH } \\
\text { release }\end{array}$ & $\begin{array}{l}\text { Decreased intra- } \\
\text { ocular pressure }\end{array}$ & $(35)$ \\
Pituitary & $(36)$ & $(38)$ \\
Eye & &
\end{tabular}

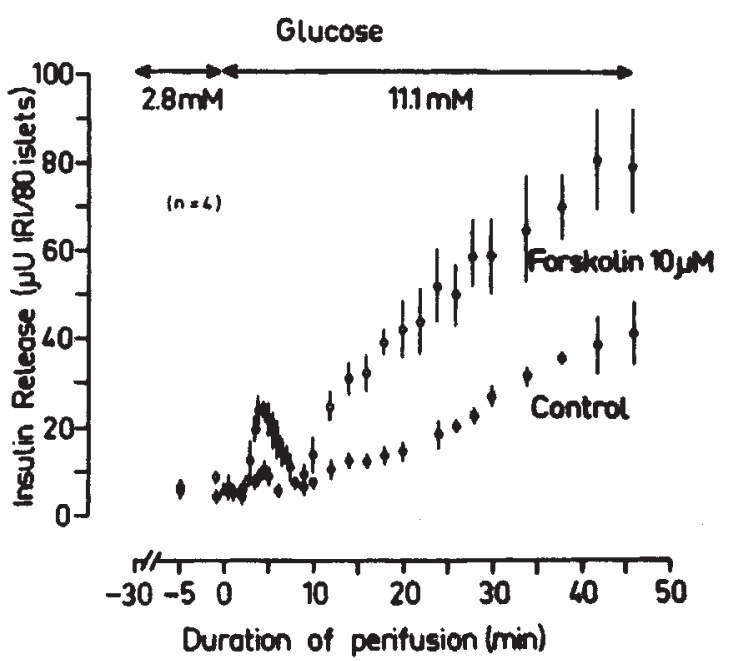

Fig. 6. Effect of forskolin on insulin release in perifused rat pancreatic islets (from 19)

Data from studies in humans are few at present and most of them are available only in abstract form. Reviewing their results must, therefore, be considered as only preliminary and a final conclusion on the validity of forskolin for treatment of human diseases has to wait until more clinical data are available.

Cardiovascular: Linderer and coworkers (22) reported that forskolin improved coronary blood flow and myocardial function without increase of myocardial oxigen consumption in 6 patients undergoing diagnostic cathederization of the heart. Eye: In man Capriolo and Sears (23) reported that forskolin, when administered topically lowered the intraoccular pressure. Respiratory tract: Inhalation of forskolin by asthmatics improved respiration after provocation of bronchospasm with methacholine as observed by Lichey and coauthors (24). Skin: Finally forskolin was reported by Bonczowitz and Methner (25) to improve symptoms in 4 patients with psorias.
It will be of interest whether or not these very preliminary clinical results will be confirmed and whether or not further clinical uses will be added.

Returning to the uses of Coleus species in traditional Ayurvedic medicine, at least from the results obtained in animal experiments, it is possible that the claimed therapeutic effects in some uses could be explained by the action of forskolin and/or coleonol on the cAMP-system in related tissues.

\section{References}

(1) Ammon, H. P. T., Kemper, F. H. (1982) Med. Welt 1, 148-153.

(2) Dhar, M. L., Dhawan, B. N., Prasad, C. R., Rastogi, R. P., Singh, K. K., Tandon, J. S., (1974) Indian J. Exp. Biol. 12, 512523.

(3) Dubey, M. P., Srimal, R. C., Patnaik, G. K., Dhawan, B. N. (1974) Indain J. Pharm. 6, 15.

(4) Bhat, S. V., Bajwa, B. S., Dornauer, H., de Souza, N. J. (1977) Tetrahedron Lett. 19, 1669-1672.

(5) Tandon, J. S., Dhar, M. M., Ramakumar, S., Venkatesan, K. (1977) Indian J. Chem. 15B, 880-883.

(6) Saksena, A. K., Green, M. J., Shue, Ho-Jane, Wong, J. K. (1985) Tetrahedron Letters 26, 551-554.

(7) Lindner, E., Dohadwalla, A. N., Bhattacharya, B. K. (1978) Arzneim.-Forsch. 28, 284-289.

(8) Dubey, M. P., Srimal, R. C., Nityanand, S., Dhawan, B. N. (1981) J. Ethnopharmacology 3, 1-13.

(9) Seamon, K. B., Daly, J. W. (1981) J. Cycl. Nucl. Res. 7, 201 224.

(10) de Souza, N. J., Dohadwalla, A. N., Reden, J. (1983) Med. Res. Rev. 3, 201-219.

(11) Daly, J. W. (1984) in Advances in Cyclic Nucleotide and Protein Phosphorylation Research, Vol. 17 (Greengard, P. et al., eds.), pp. 81-89, Raven Press, New York.

(12) Stiles, G. L., Caron, M. G., Lefkowitz, R. I. (1984) Physiol. Rev. $64,661-743$.

(13) Jakobs, K. H., Aktories, K., Schultz, G. (1984) in Advances in Cyclic Nucleotide and Protein Phosphorylation Research, Vol. 17 (Greengard, P. et at al., eds.), pp. 135-143, Raven Press, New York.

(14) Ross, E. M., Gilman, A. G. (1980) Ann. Rev. Biochem. 49, 533 564.

(15) Seamon, K. B., Padgett, W., Daly, I. W. (1981) Proc. Nat. Acad. Sci. USA. 78, 3363-3367.

(16) Litosch, I., Hudson, T. H., Mills, I., Li, S.-Y., Fain, I. N. (1982) Mol. Pharmacol. 22, 109-115.

(17) Dardler, F. J., Mahan, L. C., Koachman, A. M., Insel, P. A. (1982) J. Biol. Chem. 257, 11901-11907.

(18) Seamon, K. B., Wetzel, B. (1984) in Advances in Cyclic Nucleotide and Protein Phosphorylation Research, Vol. 17 (Greengard, P. et al., eds.), pp. 91-99, Raven Press, New York.

(19) Ammon, H. P. T., Müller, A. B. (1984) Naunyn-Schmiedeberg's Arch. Pharmacol. 326, 363-367.

(20) Fradkin, I., Cook, G. H., Kilhoffer, M.-C., Wolff, I. (1982) Endocrinology 111, 849-856.

(21) Agarwal, K. C., Parks, R. E. (1983) Int. J. Cancer 32, 801-804.

(22) Linderer, T., Biamino, G., Brueggemann, T., Schroeder, R. (1983) Z. Kardiol. 72, Suppl. 2, 53.

(23) Caprioli, I., Sears, M. (1983) Lancet 1, 958-960.

(24) Lichev, I., Friedrich, T., Priesnitz, M., Biamino, G., Usinger, P., Huckauf, H. (1984) Lancet 2, 167.

(25) Bonczkowitz, H., Methner, G. F. (1984) Akt. Dermatol. 10, 121.

(26) Mills, D. C. B. (1982) in Cyclic Nucleotides, Part II: Physiology and Pharmacology (Kebabian, I. W., Nathanson, I. A., eds.), pp. 723-761, Springer Verlag Berlin, Heidelberg, New York.

(27) Fain, I. N. (1982) in Cyclic Nucleotides, Part II: Physiology and Pharmacology (Kebabian, I. W., Nathanson, I. A., eds.), pp. 98150, Springer Verlag Berlin, Heidelberg, New York. 
(28) Katz, A. M. (1982) in Cyclic Nucleotides, Part II: Physiology and Pharmacology (Kebabian, I. W., Nathanson, I. A., eds.), pp. 347-364, Springer Verlag Berlin, Heidelberg, New York.

(29) Namm, D. H. (1982) in Cyclic Nucleotides, Part II: Physiology and Pharmacology (Kebabian, I. W., Nathanson, I. A., eds.), pp. 683-690, Springer Verlag Berlin, Heidelberg, New York.

(30) Malaisse, W. J., Malaisse-Lagae, F. (1984) Experientia 40, 10681075.

(31) Siegl, A. M., Daly, J. W., Smith, I. B. (1982) Mol. Pharmacol. 21, 680-687.

(32) Wiedenkeller, D. E., Sharp, G. W. G. (1983) Endocrinology 113 , $2311-231$.

(33) Holmes S. D., Field, I. B. (1982) in Cyclic Nucleotides, Part II: Physiology and Pharmacology (Kebabian, 1. W., Nathanson, I. A., eds.), pp. 567-597, Springer Verlag Berlin, Heidelberg, New York.
(34) Brown, R. L. (1982) in Cyclic nucleotides, Part II: Physiology and Pharmacology (Kebabian, I. W., Nathanson, I. A. eds.), pp 623 650 Springer Verlag Berlin, Heidelberg, New York.

(35) Labrie, F., Borgeat, P., Dronin, I., Lagace, L. et (1982) In Cyclic Nucleotides, Part II: Physiology and Pharmacology (Kebabian, I. W., Nathanson, I. A. eds.), pp. 525-566, Springer Verlag Berlin, Heidelberg, New York.

(36) Farber, D. B. (1982) In Cyclic Nucleotides, Part II: Physiology and Pharmacology (Kebabian, I. W., Nathanson, I. A., eds.), pp. 465-524, Springer Verlag Berlin, Heidelberg, New York.

(37) van Sande, I., Cochaux, P., Dumont, I. E. (1982) FEBS Lett. $150,137-141$.

(38) Moriwaki, K., Itoh, Y., Sayomi, I., Ichihara, K. (1982) Life Sci. $30,2235-2240$.

(39) Heisler, S., Reisine, T. (1984) J. Neurochem. 42, 1659-1666. 